\title{
KUALITAS SUMBERDAYA MANUSIA MENENTUKAN KEMAJUAN SUATU NEGARA
}

Oleh:

Johannes Suhardjana

Fakultas Hukum Universitas Jenderal Soedirman Purwokerto

\begin{abstract}
A common way of saying 'forward state' if the country concerned can show technological and industrial goods. Excellence in the industrial field is parallel with the quality to absorb or to discover something new that is used to enchane the added value of natural resources available which will increase the welfare state. The ability to absorb and discover not will be maintained with any legally experts in the field of intellectual property rights of the human resources will not be useful enough if it is not set for a high benefit for society and the nation as whole because this is the result of the culture of human life. Human resources if be managed properly will be able to determine the progress of a nation.
\end{abstract}

Kata kunci: teknologi, industri, sumberdaya manusia, sumber daya alam, negara kesejahteraan

\section{A. Pendahuluan}

Dalam jaman modern ini, ... societies have become more interdependent, ... increasing interdependence has led to the development of more orderly procedures for regulating relations among societies, .... ${ }^{1}$ Adanya pengaruh modernisasi tadi yang berakibat adanya ketergantungan antara sesama masyarakat maupun negara, memaksa untuk saling bekerjasama, sama dan setingkat meskipun diakui adanya tingkat perkembangan teknologi yang berbeda, tingkat kemakmuran dan kebutuhan, sehingga timbullah apa yang disebut negara underdevelop, developing dan develop countries.

Kadang-kadang suatu negara tidak mau disebut dengan underdevoped atau developing countries karena ... the wide diversity of traditional values ..., ${ }^{2}$ tetapi kenyataan, dengan parameter tertentu, misalnya dengan tingkat teknologi atau pendapatan netto perkapita, terklasifikasi dengan tingkat tertentu tersebut, yang kadang-kadang menguntungkan, misal dengan adanya bantuan tanpa bunga atau malah hibah untuk 'negara miskin' tetapi juga mendatangkan 'malu' untuk mengakuinya. Ka-

\footnotetext{
1 Black, Cyril Edwin, 1966, Change as a condition of modern life (in Modernization: The Dynamic of Growth), ed. By Myron Weiner, Cambridge, Massachusets: Voice of Amarica Forum Lectures, hlm. 22. 2 Ibid., hlm. 17.
}

dang menguntungkan adalah misalnya untuk membayar cicilan hutang, negara tadi dapat melakukan atau dikenakan perpanjangan waktu untuk mencicil hutang, sehingga 'sedikit' dapat bernafas, sebab kemungkinan untuk diokupasi, dianeksasi secara factual territorial adalah sedikit sekali kemungkinannya karena ada hak asasi manusia yang merupakan indikator bagi suatu negara, dalam arti penjajahan sudah berubah bentuk ke arah yang lebih 'halus' meskipun mungkin hasilnya 'lebih besar' atau 'lebih menguntungkan, tergantung dari sisi mana penilaiannya.

Adanya negara 'maju' dan 'tidak maju' akan menimbulkan banyak permasalahan karena pada dasarnya kekuasaan cenderung untuk digunakan. Adanya perbedaan klasifikasi, dengan parameter kualitas sumberdaya manusia menim-bulkan permasalahan juga ... the problem of integration countries can be noted in two main points, First, ... the diversity to be overecome is sharper ... . Secondly, this diversity must be healed at a time when the tasks imposed on government are much greater than they were in ..., ${ }^{3}$ di samping peringatan Lord Acton yaitu ... power tends to corrupt,

\footnotetext{
3 Wriggins, Howard, 1966, National Integration, dalam Change as a Condition of Modern Life, Op.Cit., hlm. 197.
} 
but absolute power corrupts absolutely, ${ }^{4}$ kemudian Wellisz, dalam kaitannya dengan teknologi mengatakan: Technological modernization requires the introduction of new machines and new production method. To operate the new machines, new skills must be taught, and, what is even more difficult, new managerial methods must be adopted, ${ }^{5}$ seperti halnya disinggung oleh Her-mien Hadiati Koeswadji, mengenai teknologi medik, ${ }^{6}$ yang menyebabkan biaya tinggi.

Adanya modernisasi juga mengharuskan hukum, yang oleh Marc Galanter disebut dengan 'modern legal system' dan

First, modern law consists of rules that are uniform and unvarying in their application. Second, modern law is transactional. Rights and obligations are apportioned as they result from transacttions (contractual, tortuous, criminal, and so on) between parties rather than. Third, modern legal norms are universalitic. Particular instances of regulating are devised to exemply a valid standard of general applicability, rather than to express that which is unique and intuited. Thus the application of law is reproducible and predictable. Fourth, the system is hierarchical. Fith, the system is organized bureaucratically. In order to achieve uniformity, the system must operate impersonally, following prescribed procedures in each case and deciding each case in accordance with written rules. In order to permit review, written records in prescribed form must be kept in each case. Sixth, the system is rational. Sevent, the system is run by professionalks. Eighth, as the system becomes more technical and complex. Ninth, the system is amendable. Finally, let us consider the relation of law to political authority. Tenth, the system is political. Elevent, the task of finding law and applying it to concrete cases is dif-

4 Budiardjo, Miuriam, 2008, Dasar-dasar Ilmu Politik, edisi Revisi, cet. Ketiga, Jakarta: Pustaka Utama Gramedia, hlm. 107..

5 Wellisz, Stanislaw H., 1966, The modernization of Technology, dalam Change as a Condition of Modern Life, Op.Cit., hlm. 255.

6 Hermien Hadiati, Koewadji, 1998, Hukum Kedokteran (Studi tentang hubungan hokum dalam mana dokter sebagai salah satu pihak), Bandung: Citra Aditya Bakti, hlm. 43. ferentiated in personnel and technique from other government functions. Legislative, judicial, and executive are separate and distinct, ... modern law emphasized its unity, uniformity, and universality?

Masyarakat negara dalam rangka kerjasamanya, seperti yang tercermin dalam tujuan dari The General Agreement on Tariffs and Trade (GATT) dan dalam korelasinya dengan teknologi dan alih teknologi di dalam preambule, terlihat ada empat (4) tujuannya, yaitu:

1. Meningkatkan taraf hidup umat manusia;

2. Meningkatkan kesempatan kerja;

3. Meningkatkan pemanfaatan kekayaan alam dunia;

4. Meningkatkan produkasi dan tukar menukar barang $^{8}$

Berdasarkan hal tersebut diatas, maka tulisan ini akan membahas mengenai kualitas yang bagaimanakah yang dapat menentukan kemajuan suatu Negara.

\section{B. Pembahasan}

1. Beberapa hal mengenai teknologi dan kualitas sumberdaya manusia.

Adanya perbedaan pengembangan teknologi akan membawa dampak perbedaan kemampuan, sehingga bagi negara yang kurang berkembang akan menjadi 'pasar' negara yang lebih maju yang akan merupakan bentuk penjajahan 'baru' karena secara faktual atau fisik tidak terjajah tetapi secara ekonomis akan 'sangat tergantung', karenanya sebelum terlambat perlu adanya persiapan untuk alih teknologi, sebab:

a. Teknologi sebagai sumber input yang bernilai ekonomis;

b. Teknologi apabila dilihat dari output maka teknologi sebagai penampung output yang tidak ternilai secara ekonomis tanpa mengganggu kualitas input;

\footnotetext{
Galanter, Marc., The modernization of Law, dalam Change as a Condition of Modern Life, Op.Cit., hlm 168171.

8 Huala, Adolf dan A. Chandrawulan, 1995, Masalahmasalah Hukum dalam Perdagangan Internasional, cet. Kedua, Jakarta: Raja Grafindo Persada, hlm. 3-4.
} 
270 Jurnal Dinamika Hukum

Vol. 9 No. 3 September 2009

c. ... are based upon the policy of promoting the flow of technology and increasing the ability ... to acquire technology. ${ }^{9}$

Teknologi secara sempit dikaitkan dengan industri ..., it means technical knowledge or know-how-that is, knowledge related to the methods and techniques of production of goods and services, ...., ${ }^{10}$ sehingga disini termasuk juga kemampuan manusia atau 'human skills', yang dalam pengertian umum 'human skills' ini adalah merupakan bagian dari manusia atau sumberdaya manusia.

Seperti dikatakan oleh Marc Galanter di muka, khususnya yang berkaitan dengan manusia atau sumber daya manusia, yaitu pada ..., the system is run by professional ... more technical and complex ..., ataupun seperti disebutkan dalam tujuan GATT, sehingga jelaslah bahwa kualitas manusia sebagai sumberdaya sangat dibutuhkan, sedangkan pengertian teknologi dalam arti yang luas juga dibutuhkan kemampuan manusia, seperti dikatakan dalam ... the embodiment of technical knowledge. In some instances, the term 'embodied technology' is used to distinguish capital goods from technical knowledge ... ${ }^{11}$ yang juga sangat penting adalah adanya 'psychological effect'12, meskipun itu hanya merupakan 'turnkey'saja.

Adanya teknologi yang maju jelas tidak dapat ditiru atau diambil alih begitu saja tanpa seijin pemiliknya, yaitu dengan cara melalui, misalnya, foreign direct investment, joint venture, lisensi, franchise, kontrak manajemen, kontrak pemasaran, kontrak pelayanan tehnik, kontrak pengoperasian, international subcontracting, yang semuanya adalah berfungsi untuk menyerap dengan beberapa imbalan terhadap biaya teknologi yang dikeluarkan oleh si penemu teknologi dan hal ini dijamin atau didasarkan pada persetujuan internasional yang

\footnotetext{
9 United Nation Publication Sales No. E.87.II.A.21., 1987, Licence Agreement in developing Countries, New York: United Nations, hlm. 7

10 United Nation Publication Sales No. E.87.II.A.4., 1987, Transnational Corporations and Technology Tranfer: Effects and Policy Issues, New York: United Nations: hlm. 1.

11 Ibid.

${ }^{12}$ Wellisz, Stanislaw H., Op.Cit., hlm. 255.
}

diberlaukan sama bagi setiap negara terkecuali di negara tempat alih teknologi, misalnya masih merupakan 'infant industry' sesuai kriteria World Trade Organization (WTO) dan lain sebagainya yang disetujui oleh para pihak, sebagai 'lex specialis', maupun kalau ruang lingkupnya sudah besar dan disetujui oleh pihak-pihak yang mempunyai kepentingan, sesuai dengan prinsip hukum, yang berlaku.

Pada negara berkembang, yang poasti adalah adanya bayak kekuarangan, baik itu kekurangan pada teknologi maupun kekuarangan pada sumberdaya manusianya, sehingga dalam menuju kea rah industrialisasi diperlukan banyak pemecahan masalah, antara lain:

a. Pemecahan masalah dana/kapital, yang diperlukan bagi suatu pengembangan teknologi, baik itu 'membeli' ataupun membuat pelatihan bagi tenaga yang kurang dapat memakai teknologi baru, atau juga mencari teknologi baru dengan pendirian pusatpusat riset;

b. Kekurangan teknologi, untuk ini diperlukan adanya peralihan teknologi, peralihan ini dapat berujud kerjasama, pelatihan atau pun juga menjadi 'pasar' industri dari negara maju, yang sedikit demi sedikit, karena adanya efek psikologis akan dapat menumbuhkan keinginan untuk dapat mengalahkan, seperti terlihat pada partumbuhan negara yang maju 'baru' seperti Korea Selatan, Taiwan;

c. Adanya suasana yang mendukung untuk menuju proses industrialisasi, tanpa meninggalkan 'modal yang telah ada', misalnya di Indonesia adalah bidang pertanian, yang harus dikembangkan sehingga memenuhi standar yang diperlukan dalam perdagangan internasional, baik dari segi kualitas maupun kuantitasnya, bukan seperti yang terjadi selama ini, dimana bidang pertanian di 'anak tiri'kan dan mendewakan teknologi tingklat tinggi dalam industrialisasi sedangkan persiapan di dalam kurang mantap dan mapan, yang akibatnya adalah Indonesia justru mengimpor beras dan ekspor pesawat terbangnya tersendatsendaty atau kurang laku sebab di sektor 
industri ini masih jauh kalah bersaing di bidang teknologi dengan negara lain.

Mengenai pendekatan yang diperlukan dalam meningkatkan sumberdaya manusia, dapat dilakukan dengan cara pendekatan sebagai berikut:

a. Adanya pendekatan kepada pihak yang terkait dalam proses industrilisasi, yaitu pengusaha, pekerja dan pemerintah, untuk membuat suatu pola kerja dan mekanisme kerja yang efektif dan efisien;

b. Adanya pendekatan komunikasi, informasi dan edukasi, yaitu untuk memanfaatkan kemajuan teknologi sehingga ada nilai tambah yang dihasilkan;

c. Adanya pembinaan terhadap sumberdaya manusia dengan cara atau melalui pembinaan yaitu secara :

1) Jangka pendek, untuk keperluan yang mendesak;

2) Jangka menengah, untuk sumberdaya manusia yang diperlukan bagi perencanaan yang matang, dalam arti ada waktu yang cukup untuk menyediakan sumberdaya manusia yang diperlukan.

3) Jangka panjang, penyediaan sumberdaya manusia telah dirancang cukup jauh sebelumnya sehingga lebih matang dan telah sangat diperhitungkan pemanfaatannya.

\section{Manajemen sumberdaya manusia}

Untuk adanya alih teknologi untuk menuju ke arah industrialisasi diperlukan dan dibutuhkan terciptanya suatu manajemen yang baik, tertib, baik bagi piranti keras dan lunaknya (hardware dan software) agar ada sinkronisasi yang baik, serasi di antara keduanya sehingga tujuan yang akan dicapai akan lebih baik dan sesuai dengan yang dikehendaki.

Pengertian manajemen, salah satunya adalah yang diberikan oleh Koontz dan O'Donnel yaitu: Management is getting things done through the effort of other people $e^{13}$, sedang G.R. Terry memberikan batasan sebagai berikut: Management is the accomplishing of a

\footnotetext{
${ }^{13}$ Westra, Pariata., 1978, Ilmu Manajemen, Yogyakarta: BPA UGM, hlm. M4.
}

predetermined obyective through the effort of other people $e^{14}$

Adanya manajemen yang baik, dalam arti manajer mampu menggerakkan orang ataupun daya, forces yang dipunyainya untuk mencapai tujuan yang telah ditentukan, dalam arti dapat membangkitkan semangat, mendorong, memimpin, mengarahkan atau menjuruskan dan menertibkan dan juga mengerahkan fasilitas yang ada, dana atau funds, yakni menghimpun, mengatur, memelihara dan mengontrol segala sesuatu yang berhubungan dengan keperluan penyelesaian pekerjaan dalam usaha bersama untuk mencapai tujuannya.

Adanya fungsi manajemen yang bermacam-macam, misalnya G.R. Terry hanya menunjukkan empat (4) macam fungsi, yaitu planning, organizing, actuating dan controlling, sedangkan Lyndall K. Urwick ${ }^{15}$, yang lebih banyak memberikan fungsi manajemen, yaitu forecasting, planning, organizing, commaning, coordinating dan controling.

Adanya pengertian manajemen secara umum yang telah diuraikan di atas, ini juga berlaku bagi manajemen sumberdaya manusia, hanya saja sifatnya lebih khusus, karena menyangkut manusianya, oleh Hadari Nawawi, ${ }^{16}$ dikatakan ada tiga (3) pengertian mengenai sumberdaya manusia, yaitu:

a. Sumberdaya manusia (SDM) adalah manusia yang bekerja di lingkungan suatu organisasi (disebut juga personil, tenaga kerja, pekerja atau karyawan);

b. Sumberdaya manusia adalah potensi manusiawi sebagai penggerak organisasi dalam mewujudkan eksistensinya.

c. Sumberdaya manusia (SDM) adalah potensi yang merupakan aset dan berfungsi sebagai modal, non material/non financial di dalam organisasi bisnis yang dapat diujudkan menjadi potensi nyata/real secara fisik dan

\footnotetext{
${ }^{14}$ Ibid.

${ }^{15}$ Hasibuan, H. Malayu S.P.,2008, Manajemen, dasar, pengertian, dan masalah, ed. Revisi, cet. 7, Jakarta: Bumi Aksara.

${ }^{16}$ Nawawi, Hadari H., 1997, Manajemen Sumber Daya Manusia, untuk bisnis yang kompetitif, cet. Pertama, Yogyakarta: Gadjah Mada Univ. Press, hlm. 40.
} 
272 Jurnal Dinamika Hukum

Vol. 9 No. 3 September 2009

non fisik dalam mewujudkan eksistensi organisasi.

Ketiga pengertian yang ada adalah tidak bertentangan, meskipun pengertian pertama dan kedua sifatnya adalah cukup sederhana. Perbedaan sumberdaya manusia dengan sumberdaya material yang lain adalah bahwa sifatnya adalah abstrak dan tidak dapat diukur dari jumlahnya, karena mempunyai potensi yang merupakan proses dari abstraksi fisik dan psikis, kemampuannya sangat tinggi karena dapat berfikir, mempunyai gagasan, kreatifitas, inovatif, memecahkan masalah dan lain sebagainya, sehingga manusia yang mempunyai potensi tinggi secara komparatif dapat dibandingkan dengan beberapa manusia yang tidak mempunyai kemampuan potensial dan berkualitas.

Manusia juga merupakan sumberdaya yang harus disediakan biayanya, termasuk di dalamnya adalah mengenai imbalan atas kerja dan jasanya, sehingga akan dapat memberikan kontribusi secara maksimal terhadap pekerjaannya, yang akan dikomulasikan dengan harga produk yang dihasilkan, termasuk di dalamnya juga kontribusi langsung maupun yang tidak langsung.

Dari apa yang disebutkan tadi, dapatlah dikatakan bahwa yang disebut dengan manajemen sumberdaya manusia adalah suatu proses mendayagunakan manusia sebagai tenaga kerja secara manusiawi, agar potensi fisik dan psikis yang dimilikinya berfungsi maksimal bagi pencapaian tujuan dari suatu orgtanisasi atau perusahaan, dengan demikian ada korelasi timbal balik antara organisasi dan manusia dengan potensi yang dimilikinya yang bersifat abstrak dan tidak jelas batasnya, karena kemampuan manusia tidak bisa diukur, dapat di ukur dengan dengan kriteria yang sifatnya 'tergantung' dalam arti pada saat itu serta diperlukan adanya hubungan sosial positif dalam sumberdaya manusia, sebab manusia sendiri adalah subyek sosial yang menentukan.

Manajemen sumberdaya manusia adalah manajemen dalam arti khusus karena adanya faktor manusia, yang sangat penting artinya bagi suatu pencapaian tujuan di samping berbagai kendala maupun tantangan yang harus dapat diselesaikannya.

Beberapa tantangan ataupun kendala yang ada dalam manajemen sumberdaya manusia tidak bisa dilepaskan dalam korelasinya subyek manajemen yang juga makhluk sosial, karenanya tantangan atau kendala tujuan manajemen sumberdaya manusia yang ada berupa:

a. Tujuan masyarakat sebagai keseluruhan;

b. Tujuan organisasi yang bersangkutan;

c. Tujuan fungsional dalam arti tujuan manajemen sumberdaya manusia dalam suatu organisasi, dan

d. Tujuan pribadi para anggota organisasi. ${ }^{17}$

Sebagai layaknya suatu manajemen, manajemen sumberdaya manusia juga mempunyai jaringan kerja atau network, jaringan mana berupa jaringan kerja internal (internal network) dan jaringan kerja eksternal atau external network, jaringan kerja internal misalnya dalam suatu perusahaan adalah pemasok, penjual atau dapat juga konsultan perusahaan, sedangkan jaringan kerja eksternal adalah jaringan kerja di luar jaringan kerja internal, misalnya adanya joint venture, hak monopoli, lisensi dan royalty serta bentuk jaringan kerja lainnya sejauh ada di luar kerja intern organisasi. Jaringan kerja tadi diperlukan dalam rangka untuk mencapai tujuan yang telah digariskan.

Tujuan manajemen sumberdaya manusia, seperti telah disebutkan di atas yang dipertegas oleh Michael R. Carret, Norbert F. Elbert, dan Robert $\mathrm{D}$. Hatfield sebagaio ... human resource management is clearly toward to the adoption of human resources approach, through with organizations benefit in two significant ways: an increase in organizational effectiveness and the satisfaction of each employee's needs, The human resources approach. It is relatively new in management of people. ${ }^{18}$ yang secara positif apabila diklasifikasikan adalah merupakan tujuan yang terbesar sampai tujuan yang

\footnotetext{
17 Siagian, Sondang P., 1997, Manajemen sumber daya manusia, cet. Kelima, Jakarta: Bumi Aksara, hlm. 26

18 Sofjandi, Herman., Manajemen sumber daya manusia, 2008, ed. Pertama, cet. Pertama, Yogyakarta: Graha
} 
terkecil, penyebutan secara positif adalah untuk membedakan penyebutan secara negatif yang terkonotasi bahwa tujuan utama adalah bagi dirinya sendiri baru di luar dirinya.

Pencapaian tujuan yang tidak bisa dilepaskan dari setiap organisasi adalah pencapaian tujuan masyarakat dalam arti bahwa setiap organisasi harus mempunyai ke'sensitif'an atau kepekaan terhadap tuntutan sosial, kemudian baru kepada pencapaian tujuan organisasi sebab pengelolaan sumberdaya manusia adalah untuik meningkatkan efisiensi, efektifitas dan produktifitas organisasi, baik dalam satuan kerja intern maupun dalam satuan penunjang kerja organisasi secara keseluruhan atau yang biasa disebut dengan istilah 'tugas fungsional'19, kemudian baru pencapaian tujuan pribadi, sebab bagaimanapun bentuknya suatu organisasi, pelakunya adalah manusia, yang mempunyai tujuan subyektif, yang kadang-kadang tujuan subyektifnya ini lebih mengedepan, karena ia mempunyai kekuasaan, sehingga Lord Acton sampai mengatakan: Power tends to corrupt. ${ }^{20}$

\section{Tantangan teknologi dan industrialisasi}

Suatu Negara biasanya akan menekankan industri di samping produk non industri yang lain, apalagi lahan atau wilayah negara cukup sempit dan sedikit sekali mempunyai sumberdaya alam.

Pada hakekatnya industri dan teknologi adalah suatu usaha untuk menambah nilai suatu produksi ataupun pengadaan yang sangat sukar dilakukan apabila tidak lewat jasa industri ataupun dengan teknologi, yang akan menambah 'nilai' barang ataupun jasa yang ada.

Seperti halnya yang terjadi di Indonesia, tanpa mempersoalkan adanya interes pribadi ataupun adanya kesalahan kebijakan pemerintah, Indonesia adalah negara yang sangat luas wilayah teritorialnya, dengan sumberdaya alam yang melimpah dan kesuburan yang prima, sehingga $\mathrm{Ki}$ Dalangpun mengatakan 'sarwa tuwuh kang tinandur/semua yang ditanam bisa

\footnotetext{
19 Ibid., hlm. 28.

${ }^{20}$ Budiardjo, Miriam., 2008, Dasar-dasar Ilmu Politik, ed. Revisi, cet. ketiga, Jakarta: Gramedia Pustaka Utama, hlm. 107.
}

tumbuh', tetapi berkeinginan untuk membangun industri pesawat terbang dengan teknologi yang canggih hal itu bias saja dan baik tetapi sebaiknya jangan meninggalkan "modal' yang telah ada dan tinggal dikembangkan, di samping adanya keinginan atau ketertarikan akan investasi asing dengan beberapa pertimbangan, antara lain ' ... the suppression of exchange controls, guarantees on invested capital, the fact that the World Bank considers Indonesia to be one of the bestmanaged developing countries, and primarily, the archipelago's market potentials, ${ }^{21}$

Suatu negara yang akan memilih suatu jenis industri sebaiknya dengan pertimbangan yang matang dan juga dengan pertimbangan akan kemampuan diri negara yang bersangkutan, bukan karena proyeksi badan atau lembaga lain yang mempunyai ukuran standar umum, seperti halnya yang dipertimbangkan Indonesia, menurut Raillon, dan juga sebaiknay dengan pertumbuhan yang setapak demi setapak bukan dengan suatu loncatan, sebab kesiapan dana, mental (psychological schok) dan lain sebagainya akan sangat berpengaruh terhadap proses industrialisasi, pemilihan alih teknologi dirasa cukup tepat yaitu 'industrialization through technological injections, 22 ,

Proses yang ditempuh dalam industrialisasi lewat masukkan teknologi berdasar lima (5) prinsip dasar, yaitu:

a. Pelatihan ilmu dan teknologi, baik di dalam maupun di luar yang disesuaikan dengan kebutuhan negara;

b. Yang dikehendaki adalah yang jelas dibutuhkan dan berdasar pemikiran yang realistis terhadap pemilihan teknologi;

c. Teknologi yang dialihkan hanya yang dapat diterapkan pada pemecahan yang berujud (tangible problems);

d. Kemampuan untuk menemukan dianggap sangat penting, meskipun sangat riskan untuk negara yang luas wilayahnya cukup besar dan yang diinginkan adalah dalam

\footnotetext{
${ }^{21}$ Raillon, Francois., 1990, Indonesia 2000, The industries and technological challenge, Jakarta: CNPF-ETP \& Cipta Kreatif, Paris, hlm. 29.

${ }^{22}$ Ibid., hlm. 58.
} 
waktu singkat dapat menguasai teknologi yang bersangkutan;

e. Dalam suatu kurun waktu tertentu, kemampuan teknologi nasional akan dilindungi sampai dapat menunjukkan persaingan di forum internasional.

Berdasarkan hal yang telah diuraikan tersebut, maka terlihat bahwa hamper setiap negara menginginkan adanya pertumbuhan industri atau industrialisasi sebab berdasarkan hal ini maka pertumbuhan ekonomi negara akan dapat dipercepat jalannya atau akan ada akselerasi pembangunan.

\section{Simpulan}

Suatu negara secara umum dikatakan 'maju' apabila negara yang bersangkutan dapat menunjukkan adanya teknologi maupun industri yang baik, sebab secara umum juga diakui bahwa negara yang maju dalam teknologi maupun industri akan dapat 'bersaing' dengan negara lain yang kurang atau tidak maju teknologi maupun industrinya secara positif.

Keunggulan di bidang teknologi dan industri ini adalah sejajar dengan adanya kemampuan untuk menyerap ataupun untuk menemukan sesuatu yang baru yang dapat dipakai untuk mempertinggi nilai hasil sumberdaya alam yang ada sehingga akan mendapatkan 'nilai tambah' yang pada gilirannya akan menambah kesejahteraaan negara entah penambahan itu lewat pajak ataupun lewat penjualan ataupun royalty yang dibayarkan oleh pemakai jasa dan produksi yang telah diubah lewat teknologi dan industri yang ada.

Adanya kemampuan untuk menyerap dan menemukan yang baru akan dapat dipertahankan secara yuridis kalau terdapat hak-hak yang melindunginya sehingga diperlukan adanya tenaga ahli di bidang perlindungan 'intelectual property rights' yang secara umum disebut adanya profesionalisme dalam bidang hak atas bidang yang bersangkutan.

Adanya sumberdaya manusia yang memadai tidak akan berguna jika tidak diatur sedemikian rupa agar didapat kemanfaatan yang besar bagi masyarakat dan negara secara keseluruhan, karena ini adalah 'hasil budaya' dalam kehidupan manusia.

Ternyata sumberdaya manusia apabila diatur dengan baik akan dapat menentukan kemajuan suatu negara dan sumberdaya manusia yang ada adalah yang berkualitas atau dengan kata lain kualitas sumberdaya manusia menentukan kemajuan suatu negara, negara dalam hal ini adalah 'payung' tempat manusia yang diatur sesuai dengan kemajuan dan budaya yang melingkupinya atau sesuai dengan kepribadian bangsa.

\section{Daftar Pustaka}

Black, Cyril Edwin. 1966. Change as a Condition of Modern Life (In Modernization: The Dynamic of Growth). Ed. By Myron Weiner, Voice of America Forum Lectures, Cambridge, Massachusets;

Budiardjo, Miriam. 2008. Dasar-dasar Ilmu Politik. Ed. Revisi cet. Ketiga. Jakarta: Pustaka Utama Gramedia;

Galanter, Marc. 1966. The Modernization of Law, (In Modernization: The Dynamic of Growth). Ed. By Myron Weiner, Voice of America Forum Lectures, Cambridge, Massachusets;

Hasibuan, H. Malayu SP. 2008. Manajemen, dasar, Pengertian, dan masalah. Edisi revisi, cet. Ketujuh. Jakarta: Bumi Aksara;

Hermien, Hadiati Koeswadji. 1998. Hukum Kedokteran (Studi tentang hubungan hukum dalam mana dokter sebagai salah satu pihak). Bandung: Citra Aditya Bakti;

Huala, Adolf dan A. Chandrawulan. 1995. Masalah-masalah Hukum dalam Perdagangan Internasional. Cet. Kedua. Jakarta: Raja Grafindo Persada;

Nawawi, Hadari H. 1997. Manajemen Sumber Daya Manusia, untuk bisnis yang kompetitif. Cet. Pertama. Yogyakarta: Gadjah Mada univ. Press;

Raillon, Francois. 1990. Indonesia, The Industrial and technological challenge, Jakarta-Paris: CNPF-ETP \& Cipta Kreatif;

Siagian, Sondang P. 1997. Manajemen sumber daya manusia. Cet. Kelima. Jakarta: Bumi Aksara; 
Sofyandi, Herman. 2008. Manajemen Sumber Daya Manusia. Edisi Pertama, Cet. Pertama. Yogyakarta: Graha Ilmu;

United Nations Publication Sales, No. E.87.II.A. 21., 1987, Licence Agreement in Developing Countries. New York: United Nations;

United Nations Publication Sales, No. E.87.II.A. 4., 1987, Transnational Corporations and Technology Transfer: Effects and Policy Issues, New York: United Nations;

Wellisz, Stanislaw H. 1966. The Modernization of Technology (In Modernization: The Dynamic of Growth) ed. By. Myron Weiner, Voice of America Forum Lectures, Cambridge, Massachusets;

Westra, Pariata. 1978. Ilmu Manajemen. Yogyakarta: BPA UGM;

Wriggins, Howard. 1966. National Integrative (In Modernization: The Dynamic of Growth) ed. By Myron Weiner, Voice of America Forum Lectures, Cambridge, Massachusets. 